\title{
Age-specific changes in cognitive function
}

\author{
Alena Sidenkova ${ }^{1, *}$, Anara Sorokina ${ }^{1}$, Vasilisa Litvinenko $^{1}$, Artem Novoselov ${ }^{1}$, and Oleg \\ Serdyuk $^{1,2}$ \\ ${ }^{1}$ Ural State Medical University of the Ministry of Health of Russia, 620028, Repin Str., 3, \\ Ekaterinburg, Russian Federation \\ ${ }^{2}$ Sverdlovsk Regional Clinical Psychiatric Hospital, 620030, Sibirsky Tract, 8 km, Ekaterinburg, \\ Russian Federation
}

\begin{abstract}
Currently, the number of cases of pathological aging of the central nervous system, represented by a violation of cognitive functions, is increasing. But there is a social request to prolong the physical and mental activity of older people. The study of the dynamics of cognitive aging is timely and relevant. The article contains a report on a cohore non-repeating study of higher brain functions at various age periods. 148 people involved. Their age is $27-74$ years. They are right handed. We applied the screening neuropsychological method. Statistical data processing was performed using SPSS Statistics 17.0 (Mann-Whitney U-test). The dynamic heterogeneity of the cognitive profile during aging was revealed. The deterioration in the performance of the graphomotor test was the most age-specific. In older study participants, a decrease in the visual gnosis test correlated with a decrease in non-verbal intelligence. The decrease in executive functions correlated with the growth of neurodynamic disorders in elderly study participants. The results obtained are useful for differentiating normative and pathological aging of the central nervous system.
\end{abstract}

\section{Introduction}

Population aging is an important modern socio-demographic characteristic. Currently, older people are active participants in the process of social development [1]. The preservation of cognitive abilities of an elderly person is necessary to maintain their subject social activity. [2]. A systematic review of studies of older people has shown a positive correlation between "social capital" and mental health [3]. The quality of "social capital", social activity, participation in decision-making in society, lack of need for care in everyday life, the depth of social relations are associated with the quality of cognitive functions of older people $[4,5,6,7]$. Cognitive disorders limit the ability of an aging person to participate in socio-industrial processes and require additional expenses from family members, society, social services and health care, the state for the maintenance and treatment of an elderly person [8]. In Russia, the first request for medical care for cognitive deficits often occurs in the later stages of the disease $[9,10]$. The doctor has difficulty diagnosing benign cognitive dysfunction due to the lack of strict diagnostic boundaries for age-related cognitive speed.

\footnotetext{
*Corresponding author: sidenkovs@mail.ru
} 
Physiological involution changes cause "benign senile forgetfulness", "age-related memory disorders"," age-related cognitive disorders " and are fundamentally different from the onset of dementia [11]. Diagnostic criteria for age-related cognitive forms are contradictory and insufficient. Researchers and clinicians note that it is very difficult to distinguish " normal aging" from degenerative and cerebrovascular pathology [12]. This is due to the lack of sensitivity of standard neurocognitive scales. Mao believes that it is necessary to measure not only the functions of memory, speech and other cortical functions, but also the quality of concentration, sensitivity to interference, reaction speed and cognitive rigidity in older people, as well as the sensitivity of aging neurodynamic parameters of cognitive functions [13]. H. Makizako et al. it is shown that walking speed, memory, and information processing speed are independent predictors of limiting the daily instrumental activity of older people [14]. The search for ways to measure cognitive function in a normally aging elderly person led Calero-Garcia and co-authors to evaluate cognitive strategies by analyzing their ability to solve typical everyday problem situations [15]. Using this method, K. J. Kimbler et al. They offered a "random" assessment, proved the effectiveness of the everyday problems test (EPT) and the ability to perform everyday instrumental actions independently (IADLs) in a sample of adults over 50 years of age [16]. Mulligan and coauthors found that anxiety, depression, and neuroticism reduce the overall result of an older person's cognitive tests. Neuroticism and self-assessment of cognitive decline explain a unique variance within the individual, a random relationship between subjective cognitive function and objective working memory [17]. A large-scale study of aging in a large national sample of older people in England found that cognitive aging has several possible trajectories. Gender models included age, gender, education, financial status, comorbidities, physical activity, alcohol use, Smoking, and depression. Gender, age, depression, and lack of physical activity were important parameters for the rate of overall aging. Of the cognitive functions, Executive functions and global cognitive function were the most sensitive [18]. T. Dwolatzky, V. Whitehead, G. M. Doniger et al. developed a computerized neurocognitive battery. They noted that using a computer methodology to evaluate cognitive function is more accurate and time-efficient than filling out paper scales. It was found that the logical memory subtest on the Wexler scale is one of the most sensitive and predictive tests [19]. A review of research shows that there is no single methodological approach to assessing neurocognitive functions in aging. Fixing disparate indicators does not allow us to understand the process of General cognitive aging. Varako N. A. et al. applied neuropsychological assessment of A. R. Luria (praxis, gnosis, reading, calculation, attention, memory, thinking, visual-spatial and Executive functions). Heterogeneity of cognitive aging and neuropsychological mechanisms of possible compensation for reduced functions was revealed [20]. Intensive rates of demographic aging, the need to maintain social and cognitive activity of older people determine the relevance of research on normative aging. The lack of a unified methodological approach to the study of normative aging and a standardized set of cognitive assessment tests allows us to develop our own psychometric tools.

The aim of the study was to study the age dynamics of cognitive functions in working people of different ages.

\section{Materials and Methods}

The study involved 148 people, including 12 men and 136 women. The average age was $45.1+5.7$ years. Inclusion criteria: 1. Right. Criteria for non-inclusion: 1. Clinically significant somatic diseases in their history. 2. Mental disorders in their medical history. The neuropsychological (neuropsychological express method [21]) and statistical research methods were used. The results of several subtests were analyzed: "Memorizing 9 words in 
three presentations (1st, 2nd, 3rd attempt)", “Consecutive subtraction”, “Test" of Benton's visual memory, "Solution of the arithmetic problem", "Overlay images", "Target stream of associations in 1 minute", "Figure of 3 geometric shapes", " Blind clock ", "Graph-motor test ", Word playback delay ". Statistical data processing was carried out using SPSS Statistics 17.0 and Microsoft Office Excel 2007. The Mann-Whitney U-test was used to compare the results of subjects in different age groups and determine the significance of differences.

\section{Results and discussion}

The research team consisted of three cohorts. The first group is $27-40$ years old $(\mathrm{n}=37$, average age $32.7+5.2)$. The second cohort is $41-50$ years old $(n=60$, average age $45.3+$ 4.9). The third cohort is 51 years and older $(n=51$, average age $57.1+6.7)$. Evaluation of instrumental basic cognitive functions allowed not to take into account the level of education of participants.

It turned out that the general and subject-specific results of neuropsychological subtests, assessments of the dynamic characteristics of mental processes (exhaustion, inertia, impulsivity) differed between cohorts (Picture 1).

A significant difference in the graphomotor test indices was statistically confirmed between the subjects of the age group of 27-40 years and the subgroup of 41-50 years. A correlation between the number and quality of errors made during the test and the sum of a series of correct movements was introduced into the processing. For the high-quality performance of this test, a sufficient level of development of all structural and functional components of the brain, and, in particular, the "front" function of programming and control and consistent organization of movements, is required. During normal test execution, a series of movements from individual randomly controlled relationships were mastered. The elderly had much more errors and interruptions of the test than the representatives of the more "younger" subgroup, since the automation of movement, arbitrary control over the work of each link decreased, the speed increased. We found it more difficult for older people to master the skills of an automated graphics engine. When comparing the results of all neuropsychological tests, representatives of the "middle" and "old" subgroups did not show statistically significant results (Tables 1-3). The quality of graphomotor skills depends on the sufficient development of general and subtle motor skills, the consistent organization of movements, visual-spatial representations and visual memory, sufficient visual and motor control (visual-motor coordination), coordination of movements, spatial perception, spatial representations, sense of rhythm (ability manifested in the reproduction of rhythmically organized elements of the time series), "manual skill". The results of our research allow us to use the test schedule.

For further research of antero-cortical functions in people of different ages. Estimates of the strategy of the new figure correlate with predominantly non-verbal and, to a lesser extent, verbal executive functions, with the adoption of higher-order neurocognitive decisions and a decrease in the processing speed of information at an older age, which is consistent with the conclusions of other authors [30, 31,32].

\section{Conclusions}

1.Performance indicators of neuropsychological subtests of the right-handed group under study decrease unevenly as they age

2.The study revealed that the participants of the study - young hospital workers coped better with the implementation of graphomotor tests than their older colleagues. 
3. In the older participants of the study, the evaluation of the strategy of the new figure correlated with a slight decrease in predominantly nonverbal and to a lesser extent with verbal Executive functions, with a slow pace of neurocognitive decisions of the highest order and a lower speed of information processing.

\section{Back Matter}

Table 1. Significance of differences in the performance of neuropsychological subtests between subgroups 27-40 years and 41-50 years (Mann-Whitney Test)

\begin{tabular}{|l|c|c|c|c|}
\hline & $\begin{array}{c}\text { Mann-Whitney } \\
\text { U }\end{array}$ & Wilcoxon W & $\mathrm{Z}$ & $\begin{array}{c}\text { Asymp. } \\
\text { Sig. (2- } \\
\text { tailed) }\end{array}$ \\
\hline $\begin{array}{l}\text { Memorizing 9 words: 1st } \\
\text { presentation }\end{array}$ & 1054,000 & 2884,000 &,- 427 &, 669 \\
\hline $\begin{array}{l}\text { Memorizing 9 words: 2nd } \\
\text { presentation }\end{array}$ & 977,500 & 1680,500 &,- 739 &, 460 \\
\hline $\begin{array}{l}\text { Memorizing 9 words: 3rd } \\
\text { presentation }\end{array}$ & 1064,500 & 1767,500 &,- 207 &, 836 \\
\hline Serial subtraction & 802,000 & 1505,000 & $-2,457$ &, 014 \\
\hline Benton Visual Retention Test & 1006,000 & 2836,000 &,- 781 &, 435 \\
\hline $\begin{array}{l}\text { The solution of the arithmetic } \\
\text { task }\end{array}$ & 1012,500 & 1715,500 &,- 773 &, 440 \\
\hline Superimposed Images & 1004,500 & 1707,500 &,- 894 &, 371 \\
\hline $\begin{array}{l}\text { The specified flow of } \\
\text { associations for 1 min. }\end{array}$ & 1083,500 & 1786,500 &,- 197 &, 844 \\
\hline $\begin{array}{l}\text { Drawing of 3 geometric } \\
\text { shapes }\end{array}$ & 1024,500 & 1727,500 &,- 723 &, 469 \\
\hline Clock test & 1081,500 & 1784,500 &,- 232 &, 816 \\
\hline Grafomotor test & 652,500 & 1355,500 & $-3,415$ &, $001^{*}$ \\
\hline Delayed word reproduction & 985,000 & 1688,000 &,- 810 &, 418 \\
\hline$*$ p<0,05 & & & & \\
\hline
\end{tabular}

Table 2. Significance of differences in the performance of neuropsychological subtests between subgroups 27-40 years and 51 years and older (Mann-Whitney Test)

\begin{tabular}{|l|c|c|c|c|}
\hline & $\begin{array}{c}\text { Mann-Whitney } \\
\mathrm{U}\end{array}$ & $\begin{array}{c}\text { Wilcoxon } \\
\mathrm{W}\end{array}$ & $\mathrm{Z}$ & $\begin{array}{c}\text { Asymp. } \\
\text { Sig. (2- } \\
\text { tailed) }\end{array}$ \\
\hline $\begin{array}{l}\text { Memorizing 9 words: 1st } \\
\text { presentation }\end{array}$ & 676,000 & 2002,000 & $-2,341$ &, 019 \\
\hline $\begin{array}{l}\text { Memorizing 9 words: 2nd } \\
\text { presentation }\end{array}$ & 833,000 & 2159,000 &,- 949 &, 343 \\
\hline $\begin{array}{l}\text { Memorizing 9 words: 3rd } \\
\text { presentation }\end{array}$ & 884,000 & 2210,000 &,- 512 &, 609 \\
\hline Serial subtraction & 842,500 & 1545,500 &,- 744 &, 457 \\
\hline Benton Visual Retention Test & 916,000 & 2242,000 &,- 236 &, 814 \\
\hline $\begin{array}{l}\text { The solution of the arithmetic } \\
\text { task }\end{array}$ & 921,000 & 1624,000 &,- 202 &, 840 \\
\hline Superimposed Images & 913,500 & 1616,500 &,- 281 &, 779 \\
\hline $\begin{array}{l}\text { The specified flow of } \\
\text { associations for 1 min. }\end{array}$ & 835,500 & 1538,500 &,- 915 &, 360 \\
\hline
\end{tabular}




\begin{tabular}{|l|c|c|c|c|}
\hline Drawing of 3 geometric shapes & 869,500 & 1572,500 &,- 708 &, 479 \\
\hline Clock test & 907,500 & 1610,500 &,- 333 &, 739 \\
\hline Grafomotor test & 609,000 & 1312,000 & $-2,849$ &, $004^{*}$ \\
\hline Delayed word reproduction & 871,500 & 2146,500 &,- 464 &, 643 \\
\hline
\end{tabular}

* $\mathrm{p}<0,05$

Table3. Significance of differences in the performance of neuropsychological subtests between subgroups 41-50 years and 51 years and older (Mann-Whitney Test)

\begin{tabular}{|l|c|c|c|c|}
\hline & $\begin{array}{c}\text { Mann- } \\
\text { Whitney U }\end{array}$ & $\begin{array}{c}\text { Wilcoxon } \\
\text { W }\end{array}$ & $Z$ & $\begin{array}{c}\text { Asymp. } \\
\text { Sig. (2- } \\
\text { tailed) }\end{array}$ \\
\hline $\begin{array}{l}\text { Memorizing 9 words: 1st } \\
\text { presentation }\end{array}$ & 1215,000 & 2541,000 & $-1,919$ &, 055 \\
\hline $\begin{array}{l}\text { Memorizing 9 words: 2nd } \\
\text { presentation }\end{array}$ & 1202,000 & 2528,000 & $-1,709$ &, 087 \\
\hline $\begin{array}{l}\text { Memorizing 9 words: 3rd } \\
\text { presentation }\end{array}$ & 1356,500 & 2682,500 &,- 902 &, 367 \\
\hline Serial subtraction & 1232,000 & 2507,000 & $-1,740$ &, 082 \\
\hline Benton Visual Retention Test & 1433,500 & 3263,500 &,- 577 &, 564 \\
\hline $\begin{array}{l}\text { The solution of the arithmetic } \\
\text { task }\end{array}$ & 1426,500 & 2752,500 &,- 651 &, 515 \\
\hline Superimposed Images & 1434,000 & 2760,000 &,- 643 &, 520 \\
\hline $\begin{array}{l}\text { The specified flow of } \\
\text { associations for 1 min. }\end{array}$ & 1444,000 & 3274,000 &,- 509 &, 610 \\
\hline Drawing of 3 geometric shapes & 1523,000 & 3353,000 &,- 047 &, 962 \\
\hline Clock test & 1510,500 & 3340,500 &,- 126 &, 899 \\
\hline Grafomotor test & 1436,500 & 2762,500 &,- 556 &, 578 \\
\hline Delayed word reproduction & 1212,500 & 2487,500 & $-1,615$ &, 106 \\
\hline * p<0,05 & & & \\
\hline
\end{tabular}

$* \mathrm{p}<0,05$

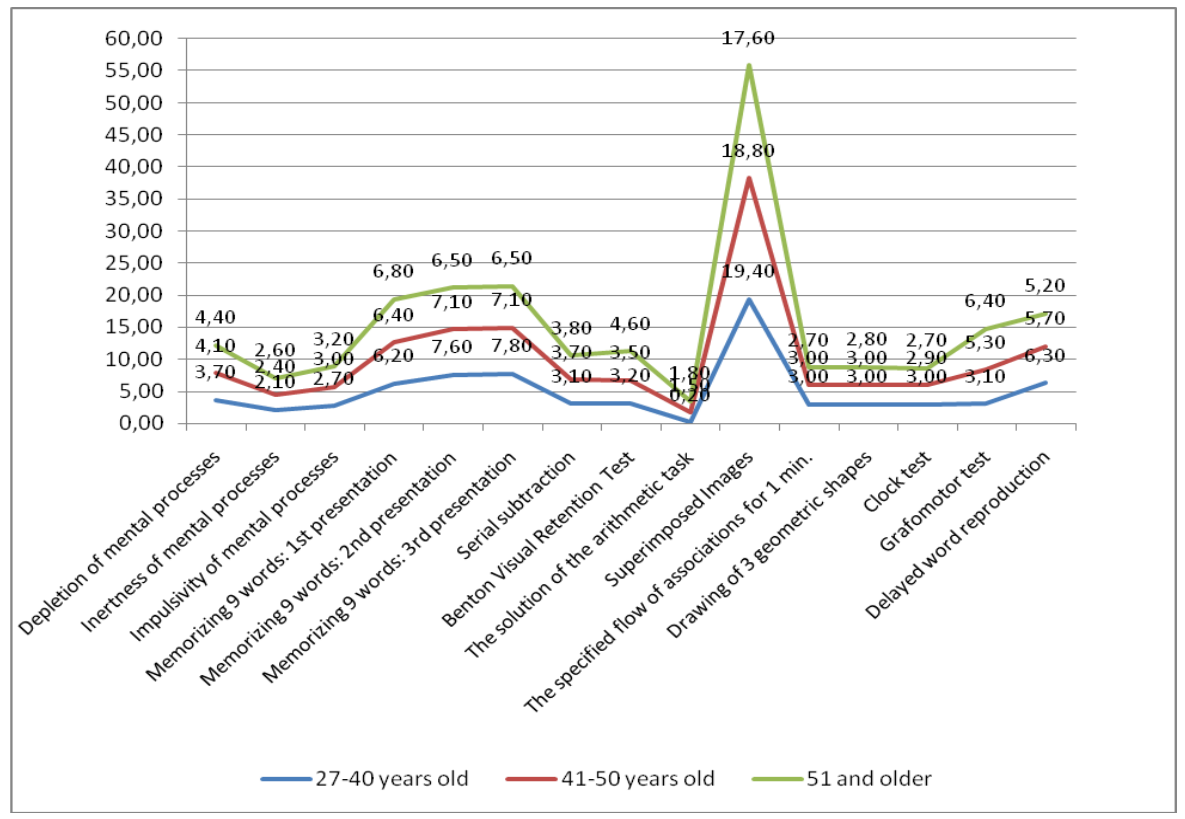

Fig. 1. Results of neuropsychological subtests performed by subjects of different ages. 


\section{Conflicts of Interest}

The authors declare no conflict of interest.

\section{References}

1. B.D. James, R.S. Wilson, L.L. Barnes, D.A. Bennett, J. Int. Neuropsychol. Soc., 17(6), 998-1005 (2011) https://doi.org/10.1017/S1355617711000531

2. R. Rose, Social Science \& Medicine, 51, 1421-1435 (2000) https://doi.org/10.1016/S0277-9536(00)00106-4)

3. F. Nyqvist, K.A. Forsman, G. Giuntoli, M. Cattan, Aging and Mental Health, 17, 394410 (2013) https://doi.org/10.1080/13607863.2012.742490

4. A. Sakamoto, U. Shigekazu, E. Okada, S. Sasaki, Zhao Wenjing, Kishi Tomoko, Kondo Katsunori, Tamakoshi Akiko, Int J Geriatr Psychiatry, 32(10), 1131-1140 (2017) https://doi.org/10.1002/gps.4576

5. C.Wang, J. Zhu, Y. Cai, D. Cui, Q. Wang, Z. Mao China. Asia Pacific Journal of Public Health, 28, 717-724 (2016) https://doi.org/10.1177/1010539516640351

6. L. Fragtiglioni, Lancet, 355, 1315-1319(2000) https://doi.org/10.1016/S01406736(00)02113-9

7. S. Takechi, K. Yoshimura, Y. Oguma, Y. Saito, M. Mimura, Advances in Alzheimer's Disease, 6, 45-51 (2017) doi: 10.4236/aad.2017.62004

8. A. Semke, A. Sidenkova, Siberian journal of psychiatry and narcology, 6, 20-24 (2011) https://dx.doi.org/10.1097\%2FJGP.0b013e3181c65864

9. A. Sidenkova, V. Litvinenko, O. Seryuk, A. Rezaikin, Psychiatria Danubina, 31, 700 (2019) http://www.psychiatria-danubina.com/articles-issues/9/2019-vol-31-sup2/1783?detalji $=1783$

10. O. Serdyuk, A. Sidenkova, Proceedings of the International Congress, 163-164 (Saint Petersburg, 2017)

11. T. Hanninen, M. Hallikainen, S. Tuomainen, M. Vanhanen, H. Soininen, Acta Neurologica Scandinavica, 106(3), $148 \quad$ (2002) DOI: 10.1034/j.16000404.2002.01225.x

12. K. Ritchie, S. Artero, J. Touchon, Neurology, 56, 37-42 (2001) DOI: https://doi.org/10.1212/WNL.56.1.37

13. C. Fu, Z. Li, Z. Mao, Int. J. Environ. Res. Public Health, 15, 231 (2018) https://doi.org/10.3390/ijerph15020231

14. H. Makizako, H. Shimada, T. Doi, K. Tsutsumimoto, S. Lee, R. Hotta, S. Nakakubo, K. Harada, S. Lee, S. Bae, K. Harada, T. Suzuki, Int. J. Environ. Res. Public Health, 12, 3002-3013 (2015), doi: 10.3390 / ijerph120303002

15. M. Calero-García, E. Navarro-González, L. Muñoz-Manzano, Archives of gerontology and geriatrics, 45, 307-318 (2007) https://doi.org/10.1016/j.archger.2007.01.061

16. K.J. Kimbler, Behav. Sci., 3, 170-191 (2013) Doi: 10.3390 / bs3010170

17. B. Mulligan, C.Smart, S. Segalowitz, S. MacDonald, Journal of the International Neuropsychological Society, 24(1), 57-66 (2018) doi:10.1017/S1355617717000613

18. P. Zaninotto, et al., J. Epidemiol Community Health, 72, 685-694 (2018) doi:10.1136/jech-2017-210116

19. T. Dwolatzky, V. Whitehead, G.M. Doniger, et al., BMC Geriatr 3, 4 (2003) https://doi.org/10.1186/1471-2318-3-4).

20. N.A. Varako, Y.P. Zinchenko, M.S. Kovyazina, O.R. Dobrushina, 25th European Stroke Conference (2016) DOI: 10.1159/000446380

21. N. To. Korsakova, E.Yu. Balashova, I.F. Roschina, Psychological research, 3(5), 2 (2009) 
22. A. Poreh, J. Levin, M. Teaford, Appl Neuropsychol Adult, 27(2), 101-107 (2018) doi: 10.1080/23279095.2018.1490288

23. R. Piers, K. Devlin, B. Ning, Y. Liu, B. Wasserman, J. Massaro, M. Lamar, C. Price, R. Swenson, R. 'Davis, D. Penney, R. Au, D. Libon, J Alzheimer's Dis., 60(4), 16111620, (2017) doi: 10.3233/JAD-170444

24. M. Lamar, O. Ajilore, A. Leow, R. Charlton, J. Cohen, J. GadElkarim, S. Yang, A. Zhang, R. Davis, D. Penney, D.J. Libon, A. Kumar, Neuropsychologia, 85, 301-9 (2016) doi: 10.1016/j.neuropsychologia.2016.03.034 